\title{
Male pronuclear formation and early embryonic development of hamster oocytes matured in vitro with gonadotrophins, amino acids and cysteamine
}

\author{
S. Kito* and B. D. Bavister ${ }^{\dagger}$ \\ Department of Animal Health and Biomedical Sciences, University of Wisconsin-Madison, \\ 1655 Linden Drive, Madison, WI 53706, USA
}

\begin{abstract}
Male pronuclear (MPN) formation in oocytes after in vitro maturation (IVM) was compared with that of matured follicular oocytes that had matured in vivo (controls). Cumulus-oocyte complexes were matured in vitro for $13 \mathrm{~h}$ in modified Tyrode's solution (TLP-PVA); cumulus-free oocytes were then incubated in $20 \%$ oviductal fluid for $3 \mathrm{~h}$, and washed and capacitated spermatozoa were added. MPN formation was significantly lower $(P<0.05)$ in IVM oocytes 3 to $12 \mathrm{~h}$ after insemination ( 0 to $34 \%$, respectively) than in control oocytes (range, $98-100 \%$ ). Female pronuclear formation was $84-100 \%$ in controls and IVM oocytes, but spermatozoa incompletely decondensed in IVM oocytes. The addition of $10 \mu \mathrm{mol} \mathrm{l}^{-1}$ during IVM, significantly increased $(P<0.05) \mathrm{MPN}$ formation (from $17 \%$ in the absence of cysteine to $47 \%$ in the presence of cysteine), but was lower than that in controls $(88 \%)$. During IVM, the addition of $10 \%$ serum or gonadotrophins (FSH and $\mathrm{LH}$ ) with or without amino acids did not support MPN formation without cysteamine, whereas the treatment with gonadotrophins and II amino acids plus $200 \mu \mathrm{mol}$ cysteamine $1^{-1}(82 \%)$ equalled controls (92\%). Development of oocytes after IVM (in 0, 10, 20\% serum) in TLP-PVA, gonadotrophins, 11 amino acids and $200 \mu \mathrm{mol}$ cysteamine $1^{-1}$ was compared with development in controls. Of the IVM treatments, $20 \%$ serum was inferior at fertilization, but yielded the highest percentage of fertilized oocytes developing to or beyond the four-cell stage $(20 \%$ serum versus controls, respectively): fertilized oocytes, $75 \%$ versus $88 \%$; $\geqslant$ four-cell embryo, $40 \%$ versus $53 \%$; blastocyst, $8 \%$ versus $14 \%$. It was concluded that during IVM, gonadotrophins plus 11 amino acids interacted with cysteamine, enhancing the decondensation of spermatozoa and MPN formation; oocytes matured in this medium with $20 \%$ serum were fertilized and some developed to the blastocyst stage.
\end{abstract}

\section{Introduction}

In vitro-matured (IVM) mammalian oocytes often have deficiencies in their cytoplasm, as indicated by their low frequency of male pronuclear (MPN) formation, low incidence of the first cleavage division after fertilization, and low developmental competence to blastocysts, compared with oocytes matured in vivo (Thibault, 1972; Thibault and Gerard, 1973; Motlik and Fulka, 1974, 1981; Rose and Bavister, 1992; Funahashi et al., 1994b; Schramm and Bavister, 1994). Although IVM oocytes in numerous species will develop to offspring after transfer of eggs into foster mothers (Fleming et al., 1985; Hanada et al., 1986; Lu et al., 1989; Yoshida et al., 1993b), the mouse is the only species in which viability similar to that of oocytes matured in vivo has been achieved in IVM oocytes (Schroeder and Eppig, 1984). In addition, the zonae pellucidae

\footnotetext{
*Present address: Department of Physiology, Cornell University, Ithaca, NY 14853, USA.

${ }^{\dagger}$ Correspondence.

Received 28 August 1996
}

of IVM oocytes display deficiencies in their ability to be penetrated by capacitated spermatozoa (De Felici and Siracusa, 1982; Zhang et al., 1991; Kito and Bavister, 1996a). Even though the capacity of the zona pellucida to be penetrated by spermatozoa can be acquired by changing maturation conditions, IVM oocytes often do not acquire full fertilization competence. Not only is MPN formation slow or low compared with oocytes matured in vivo, but also MPN and female pronuclear formation is asynchronous (Thibault, 1972; Motlik and Fulka, 1974, 1981; Leibfried and Bavister, 1983; Laurincik et al., 1994). It has been suggested from these results that IVM oocytes lack a 'male pronuclear growth factor' (MPGF; Thibault, 1972).

The fertilization competence of IVM oocytes is often enhanced by adding gonadotrophins (hCG, pregnant mares' serum gonadotrophin (PMSG), FSH or LH singly, or a combination of hCG and PMSG or FSH and LH) to the maturation medium (Thibault, 1972; Shalgi et al., 1979; Schroeder et al., 1988; Younis et al., 1989; Funahashi and Day, 1993; Schramm and Bavister, 1995). Recently, Yoshida et al. (1992, 1993a) 
showed that adding L-cysteine to simple maturation medium (Tyrode's solution) containing porcine follicular fluid enhances MPN formation by increasing the concentration of glutathione in pig oocytes. Glutathione is one of the important factors for decondensing spermatozoan nuclei after fusion of the spermatozoa with the egg (Perreault et al., 1988; Perreault, 1990). In addition, agents that facilitate the transport of thiol groups into cytoplasm, such as mercaptoethanol or cysteamine (Issel et al., 1988; Meister, 1991), enhance the fertilization and developmental competence of cow and porcine IVM oocytes (De Matos et al., 1995; Grupen et al., 1995).

In many studies, the contributions to maturation of various components of the complex tissue culture media used for IVM, including biological fluids such as serum or follicular fluid, have not been rigorously examined. Simple defined conditions are more useful for the systematic dissection of components specifically required for IVM (Bavister, 1995); these have been analysed only in mice, which have different requirements for oocyte maturation in vitro from other species (Biggers et al., 1967; Bae and Foote, 1975; Kito and Bavister, 1997). More comparative data are needed to expand our knowledge of how oocyte maturation is regulated in vitro.

Using the hamster as a model, we examined MPN formation in oocytes matured in simple chemically defined medium. The hamster was selected to provide comparative information about requirements for IVM. Completion of nuclear maturation readily occurs in simple, defined culture medium (Leibfried and Bavister, 1983; Kito and Bavister, 1996a) and conditions for in vitro insemination of IVM hamster oocytes have been established (Kito and Bavister, 1996a). Subsequently, we investigated the effects of gonadotrophins ( $\mathrm{LH}$ and FSH), amino acids, cysteamine and serum during IVM on the acquisition of oocyte competence for MPN formation. Finally, using the optimal conditions determined for MPN formation, the ability of hamster IVM oocytes to undergo fertilization, cleavage and development to the blastocyst stage was examined.

\section{Materials and Methods}

\section{Culture media}

Salts were purchased from Mallinckrodt Specialty Chemicals Co. (Paris, KY). Other chemicals were purchased from Sigma Chemical Co. (St Louis, MO), unless otherwise stated. All media were stored at $4^{\circ} \mathrm{C}$ without pyruvate, BSA, serum, cysteamine or amino acids for no more than one week. When necessary, glutamine, 11 amino acids, BSA or serum were added before equilibration of the media (see Table 1 for the 11 amino acids derived from hamster embryo culture medium 6 (HECM-6); McKiernan et al., 1995). Pyruvate was added I h prior to experiments. Cysteine or cysteamine (2-mercaptoethylamine hydrochloride; Sigma Chemical Co.) was added at the beginning of oocyte maturation. The basic medium used for maturation (maturation medium) was Tyrode's solution containing $10.0 \mathrm{mmol}$ lactate $1^{-1}$, $0.25 \mathrm{mmol}$ pyruvate $\mathrm{I}^{-1}$ and $0.1 \mathrm{mg}$ polyvinylalcohol $\mathrm{ml}^{-1}$ (TLP-PVA), as described by Bavister (1989) and Kito and Bavister (1996a, b). Maturation media were equilibrated for $8 \mathrm{~h}$ in $10 \% \mathrm{CO}_{2}, 10 \% \mathrm{O}_{2}$ and $80 \% \mathrm{~N}_{2}$ at $37^{\circ} \mathrm{C}$ under saturated humidity. TLP-PVA containing $0.1 \mathrm{mmol}$ pyruvate $\mathrm{l}^{-1}$,

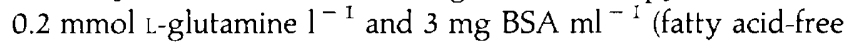
Fraction V, code 82-002, lot 48, Pentex, Kankakee, IL), designated TALP-PVA, was used for capacitation of sperm (capacitation medium), and was equilibrated under $5 \% \mathrm{CO}_{2}$ in air at $37^{\circ} \mathrm{C}$ overnight. The sperm motility factors penicillamine $\left(20 \mu \mathrm{mol} \mathrm{l}^{-1}\right)$, hypotaurine $\left(100 \mu \mathrm{mol} 1^{-1}\right)$, and epinephrine $\left(1 \mu \mathrm{mol} \mathrm{l}{ }^{-1}\right)$ (that is, PHE; Bavister, 1989) were added to capacitation medium at the beginning of sperm capacitation. The medium used for cumulus removal, co-incubation with oviductal fluid and in vitro fertilization (fertilization medium) was TLP-PVA containing $0.2 \mathrm{mmol}$ L-glutamine $\mathrm{l}^{-1}$, as described by Kito and Bavister (1996a). Culture medium was equilibrated overnight under $10 \% \mathrm{CO}_{2}, 10 \% \mathrm{O}_{2}, 80 \% \mathrm{~N}_{2}$ and high humidity at $37^{\circ} \mathrm{C}$.

\section{Collection of immature cumulus-oocyte complexes (COCs) and in vivo matured follicular COCs}

Female hamsters bred in house were kept in a $14 \mathrm{~h}$ light:10 $\mathrm{h}$ dark cycle. Mature female hamsters (2-5 months old) were injected intraperitoneally with PMSG on the morning of the post-oestrous vaginal discharge (day 1 of the oestrous cycle). The dosage of PMSG varied between 10 and 25 iu depending on the weight of animals (Barnett and Bavister, 1992). Cumulus-oocyte complexes (COCs) with immature oocytes at the germinal vesicle (GV) stage were collected 56-58 h after PMSG injection, as described by Kito and Bavister (1996a, b). Briefly, antral follicles were punctured with a 26-gauge needle in prewarmed Hepes-buffered Tyrode's-lactatepolyvinylalcohol solution (TL-HEPES; Bavister, 1989). The liberated COCs were rinsed three times in $100 \mu \mathrm{l}$ TLP-PVA. Only COCs with tightly attached cumulus cells were selected for IVM. The COCs from individual females were distributed in equal numbers into each treatment group. When COCs from two to three animals were matured together, controlled pooling (McKiernan et al., 1991) was applied so that equal numbers of COCs from individual animals were distributed into each treatment group. COCs were matured in $100 \mu \mathrm{l}$ TLP-PVA with various additives (see below), covered with $10 \mathrm{ml}$ paraffin oil in $60 \mathrm{~mm}$ Petri dishes (Falcon Plastics, No. 1007, Beckłon Dickinson and Company, Lincoln Park, NJ) for $13 \mathrm{~h}$ under $10 \% \mathrm{CO}_{2}, 10 \% \mathrm{O}_{2}$ and $80 \% \mathrm{~N}_{2}$ in saturated humidity at $37^{\circ} \mathrm{C}$. Follicular COCs matured in vivo were used as controls, and collected from PMSG-primed animals $11.5 \mathrm{~h}$ after injection of $\mathrm{hCG}$, as described by Kito and Bavister (1996a, b).

Collection of oviductal fluid and incubation of cumulus-free oocytes with oviductal fluid

The poor capacity for zonae pellucidae of hamster IVM oocytes and follicular oocytes matured in vivo to be penetrated by spermatozoa can be improved by incubating oocytes with $20 \%$ oviductal fluid for $3 \mathrm{~h}$ (Kito and Bavister, 1996a, b). The same procedure was applied in this study. Hamster periovulatory oviductal fluid was collected as described by Kito and Bavister (1996b). Oviductal fluid was stored in $0.5 \mathrm{ml}$ Eppendorf tubes at $-20^{\circ} \mathrm{C}$ until use. COCs matured in vitro or in vivo and held in equilibrated TLP-PVA were denuded of 
cumulus cells by vigorous pipetting, when cumulus expansion did not occur, or by using $1 \mathrm{mg}$ bovine testis hyaluronidase $\mathrm{ml}^{-1}$ (type 1-S, Sigma Chemical Co.) containing $0.01 \mathrm{mg}$ soybean trypsin inhibitor $\mathrm{ml}^{-1}$ (type I-S, Sigma Chemical Co.), when cumulus expansion had occurred. Cumulus-free oocytes were washed four times in $100 \mu \mathrm{l}$ equilibrated fertilization medium. Only oocytes with the first polar body (PBI) were selected for incubation with oviductal fluid. Cumulus-free oocytes were incubated at $37^{\circ} \mathrm{C}$ with $20 \%$ oviductal fluid in $20 \mu \mathrm{l}$ drops of equilibrated fertilization medium for $3 \mathrm{~h}$ under a humidified atmosphere of $10 \% \mathrm{CO}_{2}, 10 \% \mathrm{O}_{2}$ and $80 \% \mathrm{~N}_{2}$ (Kito and Bavister, 1996a). After incubation with oviductal fluid, oocytes were washed three times in $100 \mu \mathrm{l}$ equilibrated fertilization medium and inseminated with capacitated spermatozoa (see below).

\section{Preparation of spermatozoa}

Collection and preincubation of epididymal spermatozoa were performed as described by Bavister (1989) and Kito and Bavister (1996b). Briefly, the distal cauda epididymal contents from mature male hamsters were expressed into paraffin oil; they were then diluted to approximately $1.0 \times 10^{6}$ spermatozoa $\mathrm{ml}^{-1}$ into capacitation medium (TALP-PVA) that contained $3 \mathrm{mg} \mathrm{BSA} \mathrm{ml} \mathrm{ml}^{-1}$ and PHE. Spermatozoa were capacitated for $3.5-4.0 \mathrm{~h}$ at $37^{\circ} \mathrm{C}$ under $5 \% \mathrm{CO}_{2}$ in air. One male was used on each experimental day.

\section{In vitro insemination}

Cumulus-free oocytes matured in vivo were inseminated with $1.0 \times 10^{4}$ capacitated spermatozoa $\mathrm{ml}^{-1}$ (Kito and Bavister, 1996b), and cumulus-free IVM oocytes were inseminated with $5.0 \times 10^{4}$ capacitated spermatozoa ml $\mathrm{ml}^{-1}$ (Kito and Bavister, 1996a) in fertilization medium (TLP-PVA containing $0.2 \mathrm{mmol} \mathrm{L-glutamine} \mathrm{l}^{-1}$ ), with PHE added just before the addition of spermatozoa. These concentrations of spermatozoa were chosen to provide equivalent penetrations of spermatozoa into eggs (Kito and Bavister, 1996a). The sperm motility factors (PHE) were added immediately before insemination with spermatozoa. Not more than 15 oocytes were inseminated in one $100 \mu \mathrm{l}$ drop of fertilization medium. Spermatozoa and eggs were co-incubated under a humidified atmosphere of $10 \% \mathrm{CO}_{2}, 10 \% \mathrm{O}_{2}$ and $80 \% \mathrm{~N}_{2}$ at $37^{\circ} \mathrm{C}$.

Experiment 1: effects of IVM under protein-free, chemically defined conditions on subsequent MPN formation

The competence of oocytes matured in chemically defined medium (TLP-PVA) to form MPN was compared with that of oocytes matured in vivo. Cumulus-free oocytes matured in vivo or in vitro were divided into four groups and each group was incubated for to $3,6,9$ or $12 \mathrm{~h}$ after insemination. Oocytes were rinsed by vigorous pipetting $3 \mathrm{~h}$ after insemination to remove adherent but non-penetrating spermatozoa. One group of oocytes was fixed at this time. The other three groups of oocytes were transferred to $100 \mu \mathrm{l}$ drops of equilibrated HECM-6 (McKiernan et al., 1995), and cultured under 10\% $\mathrm{CO}_{2}, 10 \% \mathrm{O}_{2}$ and $80 \% \mathrm{~N}_{2}$ at $37^{\circ} \mathrm{C}$ for another 3,6 or $9 \mathrm{~h}$ (total of 6,9 and $12 \mathrm{~h}$ after insemination, respectively). The eggs were fixed at the end of culture: eggs from all groups were mounted on glass slides, stained with aceto-orcein and evaluated using Nomarski interference or phase-contrast microscopy to score for zona penetration, extrusion of the second polar body (PBII) and MPN and female pronuclear formation, as described by Kito and Bavister (1996a, b). The stages of hamster sperm nuclear decondensation scored were as illustrated by Yanagida et al. (1991). Parthenogenetically activated oocytes were eliminated from the data because of their low incidence $(<3 \%)$.

\section{Experiment 2: influence of cysteine on MPN formation of oocytes matured in chemically defined medium}

To determine whether cysteine can enhance MPN formation, COCs were matured in the presence of $0,10,50,100$ or $500\left(\mu \mathrm{mol}\right.$ L-cysteine $\mathrm{I}^{-1}$. After IVM and co-incubation with oviductal fluid oocytes were inseminated as described above. After spermatozoa had been co-incubated with eggs at $37^{\circ} \mathrm{C}$ for $4 \mathrm{~h}$, oocytes were fixed, stained and examined as in Expt 1 .

Experiment 3: effects of gonadotrophins, serum and amino acids on MPN formation of IVM oocytes

In this experiment, amino acids, serum and gonadotrophins (FSH and LH), all of which have been shown to affect cumulus expansion, nuclear maturation and oocyte morphology in hamster COCs (Kito and Bavister, 1997), were added to maturation medium to investigate their effects on sperm penetration, MPN and female pronuclear formation and PBII extrusion of IVM oocytes. The serum used was bovine calf serum (BCS; number A-2111-D, HyClone Laboratory Inc., Logan, UT), preheated at $56^{\circ} \mathrm{C}$ for $30 \mathrm{~min}$. Concentrations of gonadotrophins were $10 \mu \mathrm{g} \mathrm{FSH} \mathrm{ml}^{-1}$ (NIDDK-oFSH-19SIAFP, AFP-4II7A, $2.4 \mathrm{iu} \mu \mathrm{g}^{-1}$ ) and $10 \mu \mathrm{g} \mathrm{LH} \mathrm{ml} \mathrm{m}^{-1}$

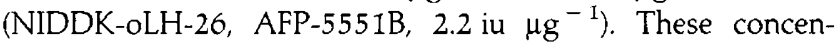
trations and combinations were based on findings from another study (Kito and Bavister, 1997). The following maturation conditions were examined: (1) medium alone (TLP-PVA); (2) TLP-PVA $+0.2 \mathrm{mmol}$ L-glutamine $\mathrm{l}^{-1}$; (3) TLP-PVA + 11 amino acids used in HECM-6 (McKiernan et al., 1995); (4) TLP-PVA +20 amino acids used in HECM-4 (McKiernan et al., 1995); (5) TLP-PVA $+0.2 \mathrm{mmol}$ L-glutamine $1^{-1}+$ gonadotrophins; (6) TLP-PVA + 11 amino acids + gonadotrophins; (7) TLP-PVA +20 amino acids + gonadotrophins; (8) TLP-PVA + $10 \%(\mathrm{v} / \mathrm{v}) \mathrm{BCS}+$ gonadotrophins; and (9) in vivo matured oocytes (see Table 1 for the amino acids used). When 20 amino acids were added to the maturation medium, osmotic pressure was adjusted by reducing the $\mathrm{NaCl}$ concentration. After incubation at $37^{\circ} \mathrm{C}$ with oviductal fluid, cumulus-free oocytes were co-incubated with spermatozoa for $4 \mathrm{~h}$, and were then fixed, stained and scored as in Expt 1.

\section{Experiment 4: influence of cysteamine on MPN formation of hamster IVM oocytes}

The effect of adding various concentrations of cysteamine to the maturation medium on MPN formation of IVM oocytes 
Table 1. Composition of media used in the analysis of the effects of gonadotrophins, bovine calf serum (BCS) and amino acids on male pronuclear formation in hamster oocytes matured in vitro (Expt 3)

\begin{tabular}{|c|c|c|c|c|}
\hline \multirow[b]{2}{*}{ Amino acid } & \multicolumn{4}{|c|}{$\begin{array}{c}\text { Concentration }\left(\mathrm{mmol} \mathrm{l}^{-1}\right) \\
\text { Treatments }\end{array}$} \\
\hline & $I$ and $8^{\text {cd }}$ & 2 and $5^{c}$ & $3^{e}$ and $6^{\mathrm{ce}}$ & $4^{\mathrm{f}}$ and $7^{\mathrm{cf}}$ \\
\hline L-alanine & $\times$ & $x$ & $\times$ & 0.28 \\
\hline L-arginine & $x$ & $x$ & $\times$ & 0.30 \\
\hline L-asparagine & $x$ & $x$ & 0.01 & 0.50 \\
\hline L-aspartic acid & $x$ & $\times$ & 0.01 & 0.50 \\
\hline L-cysteine & $x$ & $x$ & 0.01 & 0.01 \\
\hline L-glutamic acid & $x$ & $\times$ & 0.01 & 0.50 \\
\hline L-glutamine & $x$ & 0.20 & 0.20 & 0.20 \\
\hline Glycine & $x$ & $\times$ & 0.01 & 0.70 \\
\hline L-histidine & $x$ & $x$ & 0.01 & 0.10 \\
\hline L-isoleucine & $x$ & $x$ & $\times$ & 0.15 \\
\hline L-leucine & $x$ & $x$ & $\times$ & 0.20 \\
\hline L-lysine & $x$ & $x$ & 0.01 & 0.75 \\
\hline L-methionine & $x$ & $x$ & $x$ & 0.05 \\
\hline L-phenylalanine & $x$ & $x$ & $\times$ & 0.30 \\
\hline L-proline & $x$ & $x$ & 0.01 & 0.17 \\
\hline L-serine & $x$ & $x$ & 0.01 & 0.24 \\
\hline Taurine & $x$ & $x$ & 0.50 & 0.05 \\
\hline L-threonine & $x$ & $x$ & $\times$ & 0.50 \\
\hline L-tryptophan & $\times$ & $\times$ & $x$ & 0.10 \\
\hline L-valine & $x$ & $x$ & $x$ & 0.20 \\
\hline
\end{tabular}

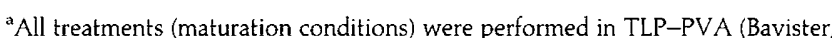
1989) containing $5.0 \mathrm{mmol}$ glucose $1^{-1}, 10 \mathrm{mmol}$ lactate $1^{-1}, 0.25 \mathrm{mmol}$ pyruvate $\mathrm{l}^{-1}$, and $0.35 \mathrm{mmol}$ phosphate $\mathrm{l}^{-1}$.

'The control, treatment 9, was in vivo matured ova.

'Treatments 5, 6, 7 and 8 also contained FSH and LH (both at $10 \mu \mathrm{g} \mathrm{ml}^{-1}$ ).

${ }^{\mathrm{d}}$ Treatment 8 also contained $10 \%$ BCS (v/v).

${ }^{\mathrm{e}}$ Treatments 3 and 6 also contained 11 amino acids used in hamster embryo culture medium 6 (HECM-6; McKiernan et al., 1995).

${ }^{\text {T}}$ Treatments 4 and 7 also contained 20 amino acids used in hamster embryo culture medium 4 (HECM-4; McKiernan et al, 1995).

was examined. Oocytes were matured in the presence of 0,25 , 50,100 or $200 \mu \mathrm{mol}$ cysteamine $1^{-1}$ in TLP-PVA supplemented with 11 amino acids and gonadotrophins (10 $\mu \mathrm{g}$ FSH ml ${ }^{-1}$ and $10 \mu \mathrm{g} \mathrm{LH} \mathrm{ml}^{-1}$ ) (see Table 1 for the 11 amino acids derived from HECM-6; McKiernan et al., 1995). The spermatozoa were co-incubated with the eggs at $37^{\circ} \mathrm{C}$ for $4 \mathrm{~h}$; eggs were then fixed, stained and scored as in Expt 1.

Experiment 5: requirements of gonadotrophins and amino acids for cysteamine-enhanced MPN formation by IVM oocytes

The influence of gonadotrophins and amino acids on cysteamine-enhanced MPN formation was examined in this experiment. Maturation conditions tested were: (1) medium (TLP-PVA) alone; (2) TLP-PVA $+200 \mu \mathrm{mol}$ cysteamine $1^{-1}$; (3) TLP-PVA $+200 \mu \mathrm{mol}$ cysteamine $1^{-1}+0.2 \mathrm{mmol}$ glutamine $\mathrm{l}^{-1}$; (4) TLP-PVA $+200 \mu \mathrm{mol}$ cysteamine $\mathrm{l}^{-1}+11$ amino acids; (5) TLP-PVA $+200 \mu \mathrm{mol}$ cysteamine $\mathrm{I}^{-1}+$ 0.2 mmol glutamine $1^{-1}+$ gonadotrophins $\left(10 \mu \mathrm{g} \mathrm{FSH} \mathrm{ml}^{-1}\right.$ and $10 \mu \mathrm{g} \mathrm{LH} \mathrm{ml}^{-1}$ ); (6) TLP-PVA $+200 \mu \mathrm{mol}$ cysteamine
$1^{-1}+11$ amino acids + gonadotrophins; and (7) in vivo matured oocytes (see Table I for the II amino acids derived from HECM-6; McKiernan et al., 1995). Cysteamine (50 $\mu \mathrm{mol}$ $1^{-1}$ ) was added to culture medium for co-incubation with oviductal fluid, based on Expt 4. A lower concentration of cysteamine than that used for COCs was added because higher concentrations cause lysis of zonae pellucidae in cumulus-free oocytes. The spermatozoa were co-incubated with the eggs at $37^{\circ} \mathrm{C}$ for $4 \mathrm{~h}$; oocytes were then fixed, stained and scored as in Expt 1 .

\section{Experiment 6: developmental competence of IVM oocytes, matured with and without $B C S$}

The developmental competence of oocytes matured in optimized medium, with or without BCS, was compared with that of the control, mature follicular oocytes. The optimized

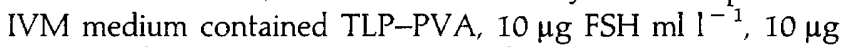
$\mathrm{LH} \mathrm{ml} 1^{-1}, 200 \mu \mathrm{mol}$ cysteamine $\mathrm{I}^{-1}$ and the 11 amino acids (from HECM-6; McKiernan et al., 1995; see Table 1), with 0, 10 or $20 \%(\mathrm{v} / \mathrm{v})$ preheated BCS. Maturation medium was equilibrated for $8 \mathrm{~h}$ at $37^{\circ} \mathrm{C}$ under $10 \% \mathrm{CO}_{2}, 10 \% \mathrm{O}_{2}$ and $80 \% \mathrm{~N}_{2}$. Gonadotrophins and amino acids were added before the medium was equilibrated, and pyruvate and cysteamine were added to the medium $1 \mathrm{~h}$ before the addition of COCs. COCs (10-15 per treatment drop) were matured for $13 \mathrm{~h}$ in $100 \mu \mathrm{l}$ maturation medium, as described in preceding sections. Mature follicular oocytes were obtained as in preceding sections. After removal of cumulus cells, oocytes were incubated at $37^{\circ} \mathrm{C}$ for an additional $3 \mathrm{~h}$ in medium containing either BCS or oviductal fluid: oocytes matured in $10 \%$ or $20 \%$ BCS (v/v) were incubated with $10 \%$ or $20 \%$ BCS $(\mathrm{v} / \mathrm{v})$, respectively; while those matured without serum, and also the control follicular oocytes matured in vivo, were incubated with $20 \%$ oviductal fluid, as described in preceding sections. This modification was introduced because of the poor penetration of oocytes matured in BCS and then exposed to hamster oviductal fluid before insemination (see Expt 3). The TLP-PVA medium used for this conditioning step also contained $50 \mu \mathrm{mol}$ cysteamine $\mathrm{l}^{-1}$ and $0.2 \mathrm{mmol}$ L-glutamine $\mathrm{l}^{-1}$. Glutamine was added to the culture medium before equilibration. After this, all oocytes were washed four times in $100 \mu \mathrm{l}$ of equilibrated, protein-free, TLP-PVA and inseminated with capacitated spermatozoa in fertilization medium (TLP-PVA), with PHE added just before adding spermatozoa. After co-incubating the oocytes with spermatozoa for $3 \mathrm{~h}$ at $37^{\circ} \mathrm{C}$, oocytes were washed four times in equilibrated embryo culture medium (HECM-6; McKiernan et al., 1995), while removing attached but non-penetrated spermatozoa by vigorous pipetting (Barnett and Bavister, 1992). All oocytes were cultured in $100 \mu \mathrm{l}$ HECM-6 overlaid with paraffin oil in $60 \mathrm{~mm}$ Petri dishes. Embryo culture dishes had been pre-equilibrated for $8 \mathrm{~h}$ under $10 \% \mathrm{CO}_{2}, 5 \% \mathrm{CO}_{2}$ and $85 \% \mathrm{~N}_{2}$. Embryos were scored for the first cleavage division $24 \mathrm{~h}$ after insemination. Uncleaved oocytes were fixed, stained and scored for fertilization as described by Kito and Bavister (1996b). Oocytes fused with spermatozoa and those that had developed to the two-cell stage $24 \mathrm{~h}$ after insemination were scored as fertilized. In hamsters, oocytes that develop 
to the two-cell stage are considered fertilized, because parthenogenetically activated oocytes do not undergo the first cleavage division (Yoo, 1990). Two-cell embryos that had developed $24 \mathrm{~h}$ after insemination were transferred into new culture drops of HECM- 6 and cultured for another $72 \mathrm{~h}$ (total of $96 \mathrm{~h}$ after insemination). Embryo morphology $96 \mathrm{~h}$ after insemination (two-, four- or eight-cell embryos, morulae and blastocysts) was scored using a dissecting microscope. The experiment was replicated seven times.

\section{Statistical analysis}

Each experiment was replicated at least four times. All data were calculated as percentages of (I) inseminated oocytes, for zona pellucida penetration and fertilization, or (2) penetrated oocytes, for MPN and female pronuclear formation, or (3) fertilized oocytes, for cleavage development. All percentage data were transformed using arcsine transformation to control unequal variance (Tukey-Freeman transformation; Zar, 1984) and then analysed by two-way analysis of variance using the SAS program. Each experimental day (that is, each male) was designated as a block. The least significant difference (LSD) test was used for multiple comparisons, and a probability of $P<0.05$ was considered as statistically significant.

\section{Results}

Experiment 1: effects of IVM under protein-free, chemically defined conditions on subsequent MPN formation

There were no significant differences in zona pellucida penetration $(94-100 \%)$ and PBII extrusion $(80-100 \%)$ between oocytes matured in vivo and in vitro, and no differences for each of these variables between the times examined (data not shown). At the times examined, almost all oocytes matured in vivo that were penetrated had male and female pronuclei (Fig. 1). After co-incubating the spermatozoa and eggs for $3 \mathrm{~h}$, $80 \%$ of penetrated IVM oocytes had a female pronucleus, which was significantly different $(P<0.05)$ from oocytes matured in vivo at this time, whereas no MPN formation was observed. Six, 9 or $12 \mathrm{~h}$ after co-incubating the spermatozoa and eggs, the percentages of female pronuclear formation in IVM oocytes were not significantly different from those of oocytes matured in vivo $(98-100 \%)$. In contrast, the maximum percentage of MPN formation in IVM oocytes was $34 \% 12 \mathrm{~h}$ after insemination, which was significantly lower $(P<0.05)$ than female pronuclear (100\%) and MPN (100\%) formation in oocytes matured in vivo and female pronuclear formation $(100 \%)$ in IVM oocytes. When sperm nuclear transformation was examined carefully, nuclei were observed to have enlarged to some extent but had not fully decondensed even $12 \mathrm{~h}$ after insemination (Fig. 2a). In some cases, $12 \mathrm{~h}$ after insemination, a pronucleus-like structure with nucleoli was observed around the decondensed mid-region of the sperm head without decondensation of the anterior and posterior sperm head regions (Fig. 2b).

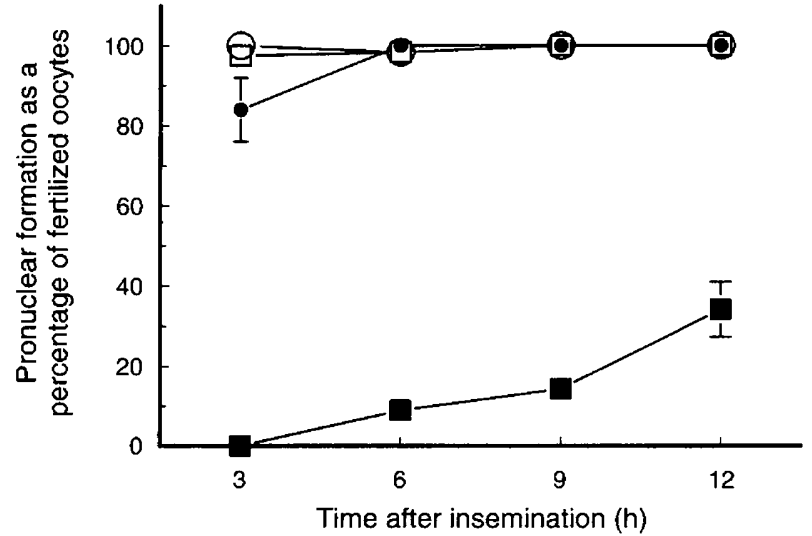

Fig. 1. Male and female pronuclear formation in cumulus-free hamster oocytes in vivo ( $\square$, male pronuclei; $\bigcirc$, female pronuclei) and in vitro ( $\boldsymbol{\square}$, male pronuclei; 0 , female pronuclei) $3,6,9$ and $12 \mathrm{~h}$ after insemination with capacitated spermatozoa. Follicular oocytes matured in vivo were collected from ovaries $11.5 \mathrm{~h}$ after hCG injection, cumulus cells were removed, and oocytes were inseminated with $1.0 \times 10^{4}$ spermatozoa $\mathrm{ml}^{-1}$ after incubation with oviductal fluid for $3 \mathrm{~h}$. Oocytes matured in vitro were matured in TLP-PVA for $13 \mathrm{~h}$, cumulus cells were removed and oocytes were inseminated with $5.0 \times 10^{4}$ spermatozoa $\mathrm{ml}^{-1}$ after $3 \mathrm{~h}$ incubation with oviductal fluid for $3 \mathrm{~h}$. Oocytes were washed $3 \mathrm{~h}$ after insemination, transferred into hamster embryo culture medium 6 (HECM-6) and cultured for another 3,6 or $9 \mathrm{~h}$ (total of 6,9 or $12 \mathrm{~h}$ after insemination, respectively). The numbers of oocytes matured in vitro examined were $44,45,41$ and 43 at $3,6,9$ and $12 \mathrm{~h}$, respectively. The numbers of oocytes matured in vivo examined were $46,48,45$ and 48 at $3,6,9$ and $12 \mathrm{~h}$, respectively. Significant differences between treatments were as follows:

$\begin{array}{lcccc}\begin{array}{l}\text { In vitro male pronuclear } \\ \text { formation versus } \\ \text { in vivo MPN }\end{array} & 3 \mathrm{~h} & 6 \mathrm{~h} & 9 \mathrm{~h} & 12 \mathrm{~h} \\ \begin{array}{c}\text { In vitro MPN versus } \\ \text { in vitro female }\end{array} & P<0.05 & P<0.05 & P<0.05 & P<0.05 \\ \begin{array}{c}\text { pronuclear formation } \\ \text { versus }\end{array} & & & & \\ \begin{array}{c}\text { In vitro MPN versus } \\ \text { in vivo FPN }\end{array} & P<0.05 & P<0.05 & P<0.05 & P<0.05 \\ \begin{array}{c}\text { In vitro FPN versus } \\ \text { in vivo MPN }\end{array} & P<0.05 & P>0.05 & P>0.05 & P>0.05 \\ \begin{array}{c}\text { In vitro FPN versus } \\ \text { in vivo FPN }\end{array} & P<0.05 & P>0.05 & P>0.05 & P>0.05 \\ \begin{array}{c}\text { In vivo FPN versus } \\ \text { in vivo MPN }\end{array} & P>0.05 & P>0.05 & P>0.05 & P>0.05\end{array}$

Experiment 2: influence of cysteine on MPN formation of oocytes matured in chemically defined medium

There was a significant increase in MPN formation in oocytes matured in the presence of $10 \mu \mathrm{mol}$ cysteine $1^{-1}(47 \%)$ compared with those matured in medium alone ( $17 \%, P<0.05$, Table 2) $4 \mathrm{~h}$ after insemination. However, under these same conditions, MPN formation was still significantly lower in IVM oocytes than in oocytes matured in vivo $(88 \%, P<0.05)$. The incidence of MPN formation decreased as the concentration of cysteine increased. There was no effect of cysteine on female pronuclear formation $(85-97 \%)$ nor on extrusion of the second 

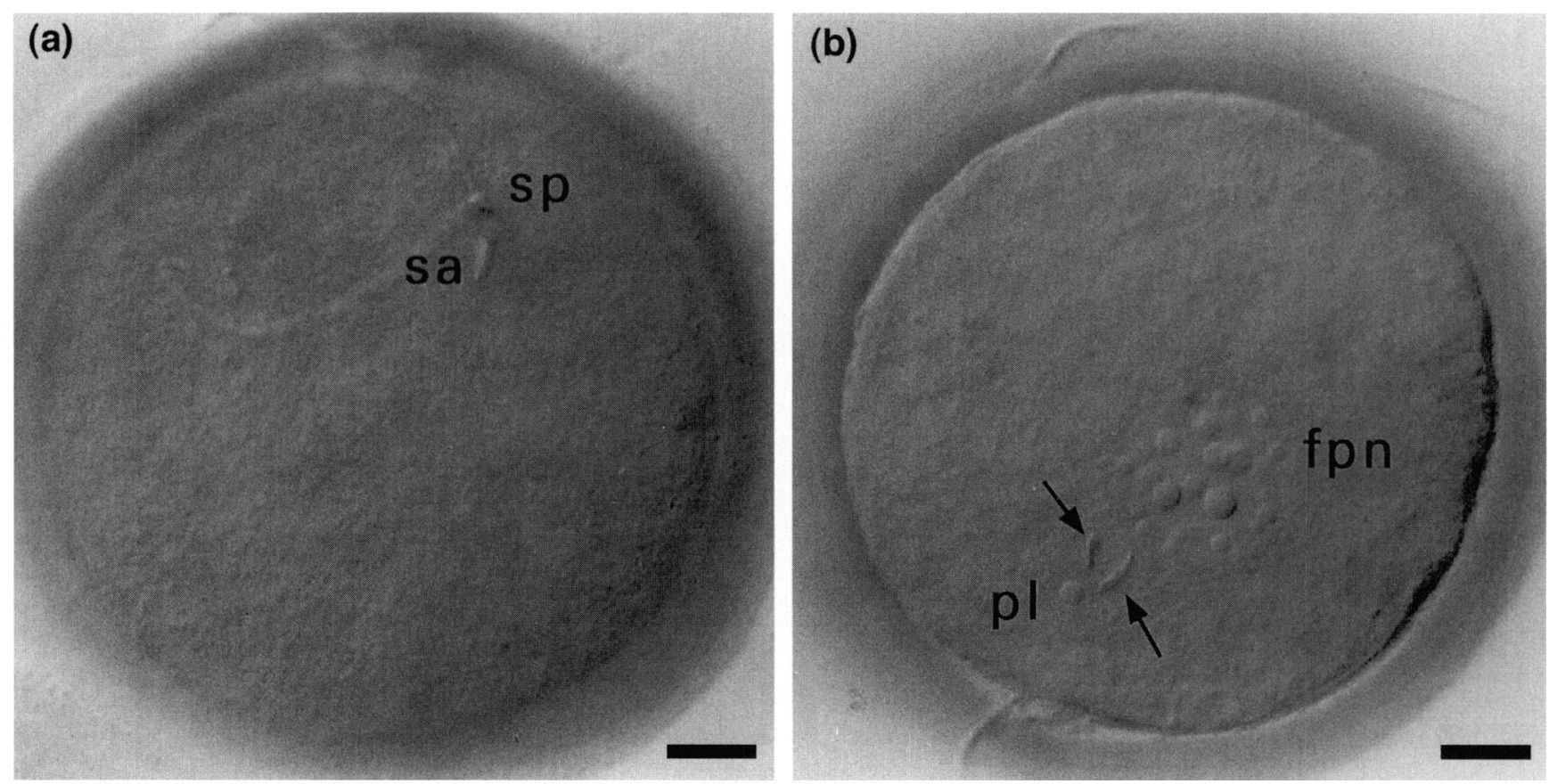

Fig. 2. Representative pictures (by Nomarski interference microscopy, $\times 400$ ) of nuclei of spermatozoa in hamster oocytes matured in vitro. Cumulus-oocyte complexes were matured for $13 \mathrm{~h}$ in TLP-PVA, then cumulus cells were removed. Cumulus-free oocytes were co-incubated with $20 \%$ oviductal fluid for $3 \mathrm{~h}$ and inseminated with capacitated spermatozoa. (a) Nucleus of a spermatozoon in the ooplasm $6 \mathrm{~h}$ after insemination. The mid-region of the head of the spermatozoon has undergone decondensation while the anterior (sa) and posterior portion (sp) of the head have not. (b) Nucleus of a spermatozoon in the ooplasm $12 \mathrm{~h}$ after insemination. The female pronucleus (fpn) has formed fully whereas the head of the spermatozoon has formed a pronucleus-like structure ( $\mathrm{pl}$ ) without decondensing the anterior and posterior portions of the head (arrows). Scale bars represent $10 \mu \mathrm{m}$.

Table 2. Effects of cysteine on the fertilization of hamster oocytes matured in vitro (Expt 2)

\begin{tabular}{|c|c|c|c|c|c|c|}
\hline \multirow{2}{*}{$\begin{array}{l}\text { Site of } \\
\text { maturation" }\end{array}$} & \multirow{2}{*}{$\begin{array}{c}{[\text { Cysteine }]} \\
\left(\mu \mathrm{mol} 1^{-1}\right)\end{array}$} & \multirow[b]{2}{*}{$N^{b}$} & \multicolumn{4}{|c|}{ Number of eggs } \\
\hline & & & Penetrated $^{c}$ & With MPN ${ }^{d}$ & With FPN ${ }^{d}$ & With PBII ${ }^{\mathrm{d}}$ \\
\hline In vitro & 0 & $5 I$ & $72 \pm 6^{\circ}$ & $17 \pm 8^{e, g}$ & $97 \pm 3$ & $84 \pm 8$ \\
\hline In vitro & 10 & 51 & $93 \pm 3^{f, g}$ & $47 \pm 9^{f}$ & $93 \pm 3$ & $93 \pm 3$ \\
\hline In vitro & 50 & 56 & $92 \pm 5^{t, g}$ & $43 \pm 13^{\mathrm{F} x}$ & $97 \pm 3$ & $85 \pm 3$ \\
\hline In vitro & 100 & 54 & $91 \pm 5^{8}$ & $40 \pm 10^{f y}$ & $96 \pm 2$ & $96 \pm 2$ \\
\hline In vitro & 500 & 52 & $100 \pm 0^{\gamma}$ & $9 \pm 5^{e^{\prime}}$ & $96 \pm 2$ & $95 \pm 4$ \\
\hline In vivo & - & 97 & $71 \pm 3^{e, g}$ & $88 \pm 6^{\mathrm{h}}$ & $85 \pm 5$ & $80 \pm 7$ \\
\hline
\end{tabular}

In vitro, $13 \mathrm{~h}$ of in vitro maturation; in vivo, $11.5 \mathrm{~h}$ after hCG injection; eggs from all sources were denuded of cumulus cells after maturation, further incubated with $20 \%$ oviductal fluid for $3 \mathrm{~h}$, and then inseminated with capacitated spermatozoa (in iitro and in vivo matured oocytes were inseminated with $5.0 \times 10^{4}$ and $1.0 \times 10^{4}$ spermatozoa $\mathrm{ml}^{-1}$, respectively).

${ }^{b}$ The total number of oocytes inseminated. (Only mature oocytes were inseminated: after $13 \mathrm{~h}$ of in vitro maturation, cumulus removal and $3 \mathrm{~h}$ co-incubation with oviductal fluid, oocytes with polar body I (PB:) were inseminated; $4 \mathrm{~h}$ later, eggs were fixed and stained for microscope observation of fertilization.)

'Values are percentages of the total number of eggs inseminated.

"Values are percentages of eggs penetrated.

cherentage values with different superscripts in a column are significantly different $(P<0.05)$.

Values are from a total of four replicates and are means $\pm s \in$.

Arithmetic means are shown but arcsine-transformed data were used for ANOVA.

MPN and FPN, male and female pronuclei, respectively; PBII, the second polar body. 
Table 3. Effects of gonadotrophins, amino acids and bovine calf serum (BCS) on penetration and fertilization of hamster oocytes matured in vitro (Expt 3)

\begin{tabular}{|c|c|c|c|c|c|c|}
\hline \multirow{2}{*}{$\begin{array}{l}\text { Amino } \\
\text { acids }^{\mathrm{a}}\end{array}$} & \multirow[b]{2}{*}{ Gonadotrophins $^{b}$} & \multirow[b]{2}{*}{$N^{c}$} & \multicolumn{4}{|c|}{ Number of oocytes } \\
\hline & & & Penetrated $^{d}$ & With $\mathrm{MPN}^{e}$ & With FPN ${ }^{e}$ & With $\mathrm{PBII}^{\mathrm{e}}$ \\
\hline None & - & 78 & $77 \pm 3^{\mathrm{f,g}, \mathrm{h}}$ & $4 \pm 2^{\ell, g}$ & $70 \pm 9^{f, g}$ & $86 \pm 4$ \\
\hline Gln & - & 62 & $88 \pm 4^{f}$ & $6 \pm 4^{\mathrm{f}, g}$ & $70 \pm 8^{f, g}$ & $70 \pm 5$ \\
\hline I1aa & - & 51 & $69 \pm 11^{\mathrm{f}, g, h}$ & $0 \pm o^{f, g}$ & $95 \pm 3^{\mathrm{h}, \mathrm{i}}$ & $79 \pm 12$ \\
\hline $20 a a$ & - & 62 & $79 \pm 7^{f}$ & $0 \pm 0^{g}$ & $76 \pm 7^{\mathrm{f} g \cdot \mathrm{h}}$ & $73 \pm 7$ \\
\hline Gln & + & 82 & $56 \pm 11^{\mathrm{g}, \mathrm{h}}$ & $4 \pm 4^{\mathrm{f}, \mathrm{g}}$ & $85 \pm 7^{\mathrm{f}, \mathrm{g}, \mathrm{h}, \mathrm{i}}$ & $85 \pm 7$ \\
\hline I1aa & + & 80 & $74 \pm 9^{f, g}$ & $16 \pm 10^{\mathrm{fhh}}$ & $84 \pm 7^{\mathrm{f}, \mathrm{h}, \mathrm{i}}$ & $84 \pm 7$ \\
\hline $20 \mathrm{aa}$ & + & 31 & $52 \pm 14^{\mathrm{h}}$ & $15 \pm 10^{\mathrm{h}}$ & $89 \pm 8^{f, g, h, i}$ & $65 \pm 15$ \\
\hline BCS & + & 77 & $21 \pm 7^{i}$ & $6 \pm 6^{f, g, h}$ & $56 \pm 19^{g}$ & $53 \pm 17$ \\
\hline \multicolumn{2}{|c|}{ Control oocytes (in vivo) } & 244 & $87 \pm 3^{f}$ & $92 \pm 3^{i}$ & $93 \pm 3^{i}$ & $80 \pm 10$ \\
\hline
\end{tabular}

${ }^{a} \mathrm{Gln}, 0.2 \mathrm{mmol}$ glutamine $\mathrm{I}^{-1}$; 1 Iaa, 11 amino acids used in hamster embryo culture 6 (HECM-6; McKiernan et al., 1995); 20aa, 20 amino acids used in hamster embryo culture 4 (HECM-4; McKiernan ef al, 1995$)$; BCS is $10 \%$ (v/v).

${ }^{\mathrm{b}} 10 \mu \mathrm{g} \mathrm{FSH} \mathrm{ml}{ }^{-1}$ and $10 \mu \mathrm{g} \mathrm{LH} \mathrm{ml}{ }^{-1}$.

'The total number of oocytes inseminated. (Only mature oocytes were inseminated: after $13 \mathrm{~h}$ of in vitro maturation, cumulus removal and $3 \mathrm{~h}$ co-incubation with oviductal fluid, oocytes with polar body $\mathrm{I}(\mathrm{PBI}$ ) were inseminated; $4 \mathrm{~h}$ later, eggs were fixed and stained for microscope observation of fertilization.)

${ }^{d}$ Values are percentages of the total number of oocytes inseminated.

"Values are percentages of penetrated oocytes.

f.g.h.jpercentages with different letters within a column are significantly different $(P<0.05)$.

Values are from a total of five replicates and are means \pm SE. Arithmetic means are shown but arcsine-transformed data were used for ANOVA.

MPN and FPN, male and female pronuclei, respectively; PBII, the second polar body.

polar body (PBII; $84-96 \%$ ). Zona pellucida lysis occurred at high concentrations $\left(\geq 100 \mu \mathrm{mol} \mathrm{I}^{-1}\right.$ ) of cysteine.

\section{Experiment 3: effects of gonadotrophins, BCS and amino acids on} MPN formation of IVM oocytes

Effects of gonadotrophins, BCS and amino acids on the penetration of zonae pellucidae and pronuclear formation were examined in this experiment (Table 3). Penetration was significantly reduced $(P<0.05)$ after IVM in the presence of BCS and gonadotrophins (21\%) compared with that after IVM in medium alone (77\%). MPN formation after IVM in the presence of 20 amino acids and gonadotrophins (15\%) was significantly higher $(P<0.05)$ than after IVM in medium alone $(4 \%)$, but not significantly different from that following IVM in the presence of gonadotrophins and either 11 amino acids $(16 \%)$ or BCS $(6 \%)$ (Table 3$)$. MPN formation in oocytes matured in vivo (92\%) was significantly higher $(P<0.05)$ than in IVM oocytes $(0-16 \%$, Table 3$)$. In IVM oocytes, most of the head of the spermatozoa (that is, the nucleus) was incorporated into the ooplasm but the process of sperm nuclear decondensation was severely retarded. The percentage of female pronuclear formation in oocytes matured in the presence of BCS and gonadotrophins was significantly $(P<0.05)$ lower $(56 \%)$ than in oocytes matured in vivo $(93 \%)$, but was not significantly different from that of oocytes matured in medium alone $(70 \%)$. There were no significant differences in PBII extrusion (53-86\%) among treatment groups.

\section{Experiment 4: influence of cysteamine on MPN formation of hamster IVM oocytes}

Whether cysteamine can affect MPN formation of IVM oocytes was examined after maturation with II amino acids and gonadotrophins. The highest concentration of cysteamine, $200 \mu \mathrm{mol} \mathrm{l}^{-1}$, was selected because preliminary results showed that concentrations greater than $200 \mu \mathrm{mol} \mathrm{l^{-1 }}$ caused zona pellucida lysis (data not shown). MPN formation was significantly $(P<0.05)$ improved in the presence of cysteamine (Table 4), and MPN formation in oocytes matured with $200 \mu \mathrm{mol}$ cysteamine $\mathrm{I}^{-1}(82 \%)$ was not significantly different from that of in vivo matured oocytes $(92 \%)$. There were no significant differences in female pronuclear formation (87-96\%) and PBII extrusion (82-93\%) among treatments (Table 4).

Experiment 5: requirements of gonadotrophins and amino acids for cysteamine-enhanced MPN formation by IVM oocytes

In this experiment, requirements for amino acids or gonadotrophins for the enhancement of MPN formation by cysteamine were investigated. Zona pellucida penetration (85-96\%), female pronuclear formation (87-100\%), and PBII extrusion (86-97\%) were not significantly different among treatment groups (Table 5). The percentages of MPN formation in oocytes matured with 11 amino acids (35\%) and with 11 amino acids and gonadotrophins (73\%) were significantly higher $(P<0.05)$ than those of the other IVM oocyte treatment groups (0-4\%). Although MPN formation in oocytes matured with 11 amino acids and gonadotrophins was highest among 
Table 4. Effects of cysteamine on fertilization of hamster oocytes matured in vitro (Expt 4)

\begin{tabular}{|c|c|c|c|c|c|}
\hline \multirow{2}{*}{$\begin{array}{l}\text { [Cysteamine] } \\
\left(\mu \mathrm{mol} \mathrm{l}{ }^{-1}\right)\end{array}$} & \multirow[b]{2}{*}{$N^{a}$} & \multicolumn{4}{|c|}{ Number of oocytes } \\
\hline & & Penetrated $^{\mathrm{b}}$ & With MPN ${ }^{\mathrm{c}}$ & With FPN ${ }^{\mathrm{c}}$ & With PBII ${ }^{\mathrm{c}}$ \\
\hline 0 & 99 & $64 \pm 7^{\mathrm{d}}$ & $19 \pm 10^{\mathrm{d}}$ & $87 \pm 6$ & $82 \pm 7$ \\
\hline 25 & 97 & $80 \pm 5^{\text {d,e.f }}$ & $60 \pm 9^{e}$ & $90 \pm 6$ & $89 \pm 6$ \\
\hline 50 & 102 & $73 \pm 5^{\text {d.e }}$ & $64 \pm 9^{e . f}$ & $91 \pm 5$ & $87 \pm 4$ \\
\hline 100 & 96 & $80 \pm 5^{\text {d.e.f }}$ & $60 \pm 7^{e}$ & $91 \pm 2$ & $84 \pm 6$ \\
\hline 200 & 100 & $85 \pm 3^{e . f}$ & $82 \pm 4^{f . g}$ & $96 \pm 2$ & $93 \pm 2$ \\
\hline Control oocytes (in vivo) & 307 & $89 \pm 3^{f}$ & $92 \pm 3^{8}$ & $97 \pm 1$ & $91 \pm 2$ \\
\hline
\end{tabular}

${ }^{a}$ The total number of oocytes inseminated. (After $13 \mathrm{~h}$ of in vitro maturation in Tyrode's solution containing $10.0 \mathrm{mmol}$ lactate $\mathrm{I}^{-1}$, $0.25 \mathrm{mmol}$ pyruvate $\mathrm{I}^{-1}$ and $0.1 \mu \mathrm{g}$ polyvinylalcohol ml ${ }^{-1}$ (TLP-PVA), as well as 11 amino acids used in hamster embryo culture medium 6 (HECM-6; McKiernan et al., 995), gonadotrophins (10 $\mu \mathrm{g} \mathrm{FSH} \mathrm{ml}{ }^{-1}$ and $10 \mu \mathrm{g} \mathrm{LH} \mathrm{ml}^{-1}$ ) and various concentrations of cysteamine, followed by cumulus removal and $3 \mathrm{~h}$ co-incubation with oviductal fluid, oocytes with polar body I (PBI) were inseminated; $4 \mathrm{~h}$ later, eggs were fixed and stained for microscope observation of fertilization.)

${ }^{b}$ Values are percentages of the total number of oocytes inseminated.

${ }^{c}$ Values are percentages of penetrated oocytes.

d.e.f.gercentages with different letters within a column are significantly different $(P<0.05)$.

Values are from a total of five replicates and are means \pm SE. Arithmetic means are shown but arcsine-transformed data were used for ANOVA.

MPN and FPN, male and female pronuclei, respectively; PBII, the second polar body.

Table 5. Effects of amino acids and gonadotrophins on cysteamine-enhanced fertilizability of hamster oocytes matured in vitro (Expt 5)

\begin{tabular}{|c|c|c|c|c|c|c|c|}
\hline \multirow{2}{*}{$\begin{array}{l}\text { Amino } \\
\text { acids }^{\mathrm{a}}\end{array}$} & \multirow[b]{2}{*}{ Gonadotrophins $^{b}$} & \multirow[b]{2}{*}{ Cysteamine $^{c}$} & \multirow[b]{2}{*}{$N^{d}$} & \multicolumn{4}{|c|}{ Number of oocytes } \\
\hline & & & & Penetrated $^{\mathrm{e}}$ & With MPN ${ }^{f}$ & With FPN ${ }^{f}$ & With PBII ${ }^{f}$ \\
\hline None & - & - & 100 & $85 \pm 5$ & $4 \pm 3^{8}$ & $90 \pm 7$ & $87 \pm 8$ \\
\hline None & - & + & 95 & $85 \pm 7$ & $0 \pm 0^{g}$ & $87 \pm 6$ & $86 \pm 5$ \\
\hline Gln & - & + & 90 & $88 \pm 4$ & $2 \pm 1^{g}$ & $95 \pm 3$ & $95 \pm 3$ \\
\hline 11 aa & - & + & 93 & $83 \pm 6$ & $35 \pm 9^{h}$ & $93 \pm 4$ & $90 \pm 5$ \\
\hline Gln & + & + & 97 & $88 \pm 3$ & $1 \pm 1^{g}$ & $98 \pm 1$ & $97 \pm 1$ \\
\hline 11 aa & + & + & 99 & $93 \pm 3$ & $73 \pm 5^{i}$ & $100 \pm 0$ & $97 \pm 2$ \\
\hline \multicolumn{3}{|c|}{ Control oocytes (in vivo) } & 261 & $96 \pm 2$ & $95 \pm 2^{i}$ & $99 \pm 1$ & $97 \pm 1$ \\
\hline
\end{tabular}

${ }^{\mathrm{a}} \mathrm{Gln}, 0.2 \mathrm{mmol}$ glutamine $\mathrm{I}^{-1}$; 11 aa, 11 amino acids used in hamster embryo culture medium 6 (HECM-6; McKiernan et al., 1995).

${ }^{8} 10 \mu \mathrm{gSH} \mathrm{ml}^{-1}$ and $10 \mu \mathrm{g} \mathrm{LH} \mathrm{ml} \mathrm{H}^{-1}$.

'Cysteamine concentration was $200 \mu \mathrm{mol} 1^{-t}$.

'The total number of oocytes inseminated. (Only mature oocytes were inseminated: after $13 \mathrm{~h}$ of in vitro maturation, followed by cumulus removal and $3 \mathrm{~h}$ co-incubation with oviductal fluid, oocytes with polar body I (PBI) were inseminated; $4 \mathrm{~h}$ later, eggs were fixed and stained for microscope observation of fertilization.)

'Values are percentages of total oocytes inseminated.

fValues are percentages of penetrated oocytes.

g.t.i.j. Percentages with different letters within a column are significantly different $(P<0.05)$.

Values are from a total of six replicates and are means \pm SEM.

MPN and FPN, male and female pronuclei, respectively; PBII, the second polar body.

IVM oocytes, it was significantly lower $(P<0.05)$ than that in oocytes matured in vivo $(95 \%)$.

\section{Experiment 6: developmental competence of IVM oocytes matured} with and without BCS

Oocytes matured in serum-free medium as well as the control follicular oocytes matured in vivo were fertilized at a higher frequency ( $88 \%$ and $89 \%$, respectively) than oocytes matured in $20 \%$ BCS $(75 \%, P<0.05)$. Occurrence of first cleavage division of oocytes matured in vitro $24 \mathrm{~h}$ after insemination with or without BCS (47-57\%) was significantly lower than that of follicular oocytes matured in vivo $(81 \%$, $P<0.05)$. From the four-cell stage onwards, IVM oocytes matured in $20 \%$ BCS showed numerically higher development than the other three IVM groups. For oocytes matured in the presence of either $10 \%$ or $20 \% \mathrm{BCS}$, development to the morula plus blastocyst stages $96 \mathrm{~h}$ after insemination was not 
IVM, 0\% BCS $\square$ IVM, 10\% BCS IVM, 20\% BCS Control

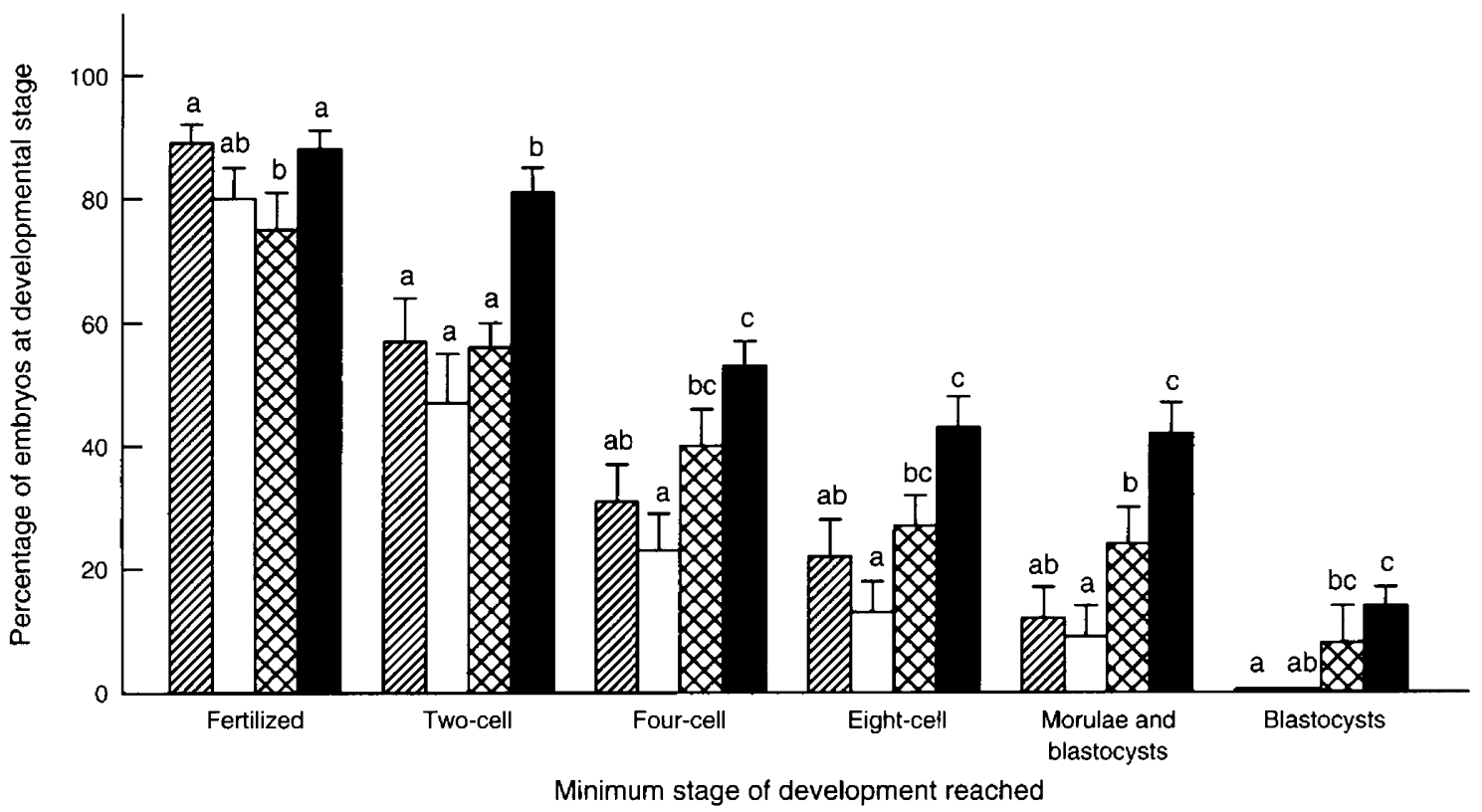

Fig. 3. Developmental competence of hamster oocytes matured in vitro (IVM), with or without bovine calf serum (BCS). Follicular oocytes were matured in the presence or absence of the indicated concentration of $\mathrm{BCS}(\mathrm{v} / \mathrm{v})$. Cumulus cells were removed from oocytes matured in vitro and in vivo. Cumulus-free oocytes, either matured without serum ( $0 \%)$ or in vivo, were further incubated with $20 \%$ oviductal fluid for $3 \mathrm{~h}$ and then inseminated. Cumulus-free oocytes matured in the presence of serum were further incubated for $3 \mathrm{~h}$ with the same concentration of serum used during in vitro maturation and then inseminated. Co-incubation of oocytes with spermatozoa was for $3 \mathrm{~h}$. Oocytes were scored for cleavage $24 \mathrm{~h}$ after insemination. Two-cell embryos were transferred to new drops of hamster embryo culture medium 6 (HECM-6; McKiernan et al., 1995) and cultured for another $72 \mathrm{~h}$. Uncleaved oocytes were fixed, stained and scored for fertilization. Stages of development: fertilized, observed at $24 \mathrm{~h}$ after insemination, expressed as a percentage of inseminated oocytes; two-cell embryo, observed $24 \mathrm{~h}$ after insemination, expressed as a percentage of fertilized oocytes $24 \mathrm{~h}$ after insemination; four-cell embryo and all later stages, observed $96 \mathrm{~h}$ after insemination expressed as a percentage of fertilized oocytes $24 \mathrm{~h}$ after insemination. Within developmental category, bars with no common superscript letters are significantly different $(P<0.05)$. Control oocytes were matured in vivo.

significantly different $(9 \%$ and $24 \%$, respectively) from that of oocytes matured in serum-free medium $(12 \%, P>0.05)$. Development to the morula plus blastocyst stages of follicular oocytes matured in vivo $(42 \%)$ was significantly higher than in oocytes matured in vitro $(P<0.05)$. Of oocytes matured in the presence of $20 \%$ serum, $8 \%$ of the fertilized zygotes had developed to the blastocyst stage $96 \mathrm{~h}$ after insemination, and this percentage was not significantly different from that of the control follicular oocytes matured in vivo $(14 \%, P>0.05$; see Fig. 3).

\section{Discussion}

Mammalian oocytes matured in vitro often have low competence for MPN formation (Thibault, 1972; Motlik and Fulka, 1974, 1981; Leibfried and Bavister, 1983; Laurincik et al., 1994). This deficiency can be improved by adding various substances such as gonadotrophins, cysteine or cysteamine in the presence of serum or follicular fluid (Thibault, 1972;
Yoshida ef al., 1992; Funahashi and Day, 1993; De Matos et al., 1995; Grupen et al., 1995). In this study, a systematic investigation was conducted to examine the competence of MPN formation after in vitro insemination of hamster oocytes matured in simple, chemically defined culture medium (TLP-PVA). Once the ability to form MPN in oocytes matured in this medium had been determined, gonadotrophins, amino acids and cysteamine were added to TLP-PVA to examine specific regulators of oocyte maturation in vitro.

In the first experiment, we showed that MPN formation in oocytes matured in protein-free, chemically defined conditions was not only less than that of follicular oocytes matured in vivo, but was also asynchronous with female pronuclear formation in the IVM oocytes. This result is consistent with previous reports (Thibault, 1972; Motlik and Fulka 1974, 1981; Leibfried and Bavister, 1983; Laurincik et al., 1994). In our study, only the mid-region of the sperm head was partially decondensed in the majority of spermatozoa incorporated into the ooplasm (stage 1, Yanagida et al., 1991). In addition, some sperm nuclei showed unusual morphology in that an MPN-like 
structure formed without full decondensation (Fig. 2b). These structures were similar to cases of abnormal MPN formation in hamster ova described by Yanagida $e$ al. (1991). On the other hand, the female pronucleus had formed in almost all oocytes matured in vitro and in vivo by $6 \mathrm{~h}$ after insemination with spermatozoa (Fig. 1). Thus, while protein-free, chemically defined medium is sufficient for the completion of nuclear maturation (Kito and Bavister, 1996a) and for female pronuclear formation, this medium is insufficient for IVM oocytes to acquire competence for MPN formation.

The mammalian sperm nucleus contains arginine and disulfide-bond-rich proteins called protamines (Yanagimachi, 1994). For decondensation of the sperm nuclei, disulfide bonds in protamine molecules have to be reduced to - $\mathrm{SH}$ groups and protamines in the sperm nucleus have to be replaced with maternal histones (Perreault et al., 1987; Zirkin et al., 1989; Perreault, 1990). Glutathione is believed to play an important role in reducing the disulfide groups of protamines in spermatozoa (Perreault et al., 1987, 1988; Yoshida, 1993. Yoshida et al., 1993a; Funahashi et al., 1994a). In hamster and pig oocytes, glutathione concentration is highly related to the ability of the egg to decondense sperm nuclei and to form MPN (Calvin et al., 1986; Perreault et al., 1987, 1988; Yoshida, 1993; Yoshida et al., 1993a). Hamster oocytes matured in vitro have a significantly lower glutathione concentration compared with the concentration in oocytes matured in vivo (Perreault et al., 1988), indicating that IVM oocytes may not have enough free thiol groups to decondense sperm nuclei. The abnormal MPN-like structures of IVM oocytes found in this study appeared to result from partial sperm nuclear decondensation, with only the decondensed portion able to interact with the maternal nuclear proteins to form a pronucleus. In normal fertilization in hamsters, male and female pronuclear formation in oocytes matured in vivo is tightly coordinated, and once sperm nuclear decondensation is complete, male and female pronuclear formation is regulated by similar mechanisms under the control of the maternal cell cycle (Wright and Longo, 1988; Longo, 1990). In hamster IVM oocytes, this process was asynchronous: female pronuclei formed in the absence of the male pronucleus, or delays occurred in sperm nuclear decondensation. Therefore, IVM conditions must be established that allow sufficient accumulation of free thiol groups (such as glutathione) needed for sperm decondensation before fertilization can be achieved in hamster IVM oocytes.

We postulated that sperm nuclear decondensation and subsequent MPN formation could be enhanced by IVM with amino acids, BCS, gonadotrophins or glutathione precursors. Cysteine, which enhances MPN formation after IVM of pig oocytes (Yoshida et al., 1992), was tested in hamsters. Although MPN formation was significantly improved by the presence of $10 \mu \mathrm{mol}$ cysteine $I^{-1}$, the frequency was still lower than in oocytes matured in vivo. One reason for low MPN formation in this series of our experiments may have been the lack of gonadotrophins or follicular fluid components used by others (Yoshida et al., 1992). Another possibility is that cysteine may have been oxidized to cystine, which is not efficiently transported into the cytoplasm (Bannai, 1984; Issel et al., 1988).

The effects of gonadotrophins, amino acids or BCS during IVM on MPN formation were examined. In a previous study
(Kito and Bavister, 1997) of hamster eggs that had not been inseminated, gonadotrophins (FSH and $\mathrm{LH}$ ) inhibited nuclear maturation in vitro in the absence of BCS or amino acids, but were stimulatory in the presence of glutamine, 11 amino acids (from HECM-6) or BCS. MPN formation in IVM oocytes in the present study was not improved by gonadotrophins, amino acids or BCS (Table 3). The 11 amino acids (from HECM-6) and 20 amino acids (from HECM-4) contained 0.01 mmol cysteine $\mathrm{I}^{-1}$ and $0.01 \mathrm{mmol}$ cysteine $\mathrm{I}^{-1}$, respectively (see Table 1 for amino acids derived from HECM-4 and HECM-6), but in contrast to results from Expt 2, neither combination of amino acids supported MPN formation. In addition, the penetration of spermatozoa through the zona pellucida and signs of egg activation (that is, female pronuclear formation and PBII extrusion) were significantly depressed after oocyte maturation with only BCS and gonadotrophins. In our in vitro fertilization system, in which eggs were first co-incubated with $20 \%$ oviductal fluid and then washed and inseminated with spermatozoa, it is possible that bovine serum inhibited zonae pellucidae penetration by masking binding sites for hamster oviductal proteins on the zonae pellucidae (Boatman and Magnoni, 1995).

Because oocytes and somatic cells do not have a transport system to import glutathione directly into the cytoplasm (De Felici et al., 1987; Meister, 1991), other compounds must be used to accumulate free thiol groups in the oocytes. Cysteamine and $\beta$-mercaptoethanol transport free thiol groups into the cytoplasm (Issel et al., 1988; Meister, 1991), and may improve fertilization and the developmental competence of pig and cow IVM oocytes by increasing the glutathione concentration in the ooplasm (Takahashi et al., 1993; De Matos et al., 1995; Grupen et al., 1995). When cysteamine was added to maturation medium with 11 amino acids and gonadotrophins, MPN formation in IVM hamster oocytes was significantly improved in a dose-dependent manner. Cysteamine at a concentration of $200 \mu \mathrm{mol} \mathrm{I}^{-1}$ improved MPN formation in IVM oocytes to that observed in oocytes matured in vivo.

Cysteamine enhanced MPN formation only in oocytes matured in the presence of both 11 amino acids and gonadotrophins. Amino acids alone or glutamine and gonadotrophins alone did not support the acquisition of competence for MPN formation. Gonadotrophins alter metabolism and amino acid transport in COCs (Hillensiö et al., 1975; Moor and Smith, 1979; Zuelke and Brackett, 1992, 1993). Amino acids (glutamine or 11 amino acids) in the presence of FSH and LH were required for completion of nuclear maturation, cumulus expansion and normal oocyte morphology in hamster IVM oocytes (Kito and Bavister, 1997). In our system, gonadotrophins may also have enhanced amino acid transport or changed the metabolic activity for the production of factors needed for sperm nuclear decondensation. The 11 amino acids included precursor amino acids (glycine, cysteine and glutamine) for glutathione synthesis (Meister, 1991). This may explain the higher frequency of MPN formation that occurred in this medium than was observed in the presence of glutamine alone.

Using our optimized IVM conditions (Expt 6) we have demonstrated, for the first time, that hamster oocytes matured in vitro are capable of completing preimplantation development to the blastocyst stage in vitro. The presence of BCS 
during the maturation phase in vitro appeared to confer some developmental advantage to embryos from the four-cell stage onwards. However, neither the control follicular ova nor the IVM oocytes developed to the morula or blastocyst stages at high percentages (Fig. 3). This was consistent with the results of an earlier report from our laboratory, which showed that hamster oocytes that have either been fertilized in vitro or have been removed from the oviduct earlier than the afternoon following ovulation and activation by spermatozoa have poor capacity to develop to the blastocyst stage in vitro (Barnett and Bavister, 1992), whereas older one-cell and two-cell embryos develop to the blastocyst stage $70-90 \%$ of the time ( $\mathrm{S}$. H. McKiernan and B. D. Bavister, unpublished).

In summary, hamster oocytes matured in protein-free, chemically defined conditions without thiol-transporting agents did not acquire full competence for fertilization; competence for MPN formation was deficient in these IVM oocytes. In most cases, the sperm nuclei were arrested during the process of decondensation. Occasionally, the decondensed portion of the sperm nuclei formed pronucleus-like structures. Apparently, an inability to decondense the nucleus of the spermatozoon completely in the ooplasm prevented MPN formation in hamster oocytes. Cysteine, gonadotrophins or amino acids (glutamine alone or 11 amino acids formulated for HECM-6) added to maturation medium improved MPN formation but not to that of oocytes matured in vivo. However, when cysteamine was added to maturation medium with the 11 amino acids and gonadotrophins, the incidence of sperm decondensation and MPN formation was increased to that observed in oocytes matured in vivo. When this medium, optimized for MPN formation, was used for IVM in the presence of $20 \%$ BCS $(\mathrm{v} / \mathrm{v})$, many of the resultant IVM oocytes were subsequently fertilized and cleaved, forming the first reported IVM hamster blastocysts.

The authors than S. H. McKiernan for valuable comments and for excellent technical support, and J. Squirrell for assistance with computer graphics. They are grateful to J. J. Eppig and R. D. Foote for critically reviewing this manuscript and D. E. Boatman for revisions. They thank NIDDK for the generous gift of ovine FSH and ovine LH. This work was done as part of the National Cooperative Program on Non-Human In vitro Fertilization and Embryo Development, funded by the National Institute of Child Health and Human Development through cooperative agreement HD22023, and also HD14235.

\section{References}

Bae IH and Foote RH (1975) Carbohydrate and amino acid requirements and ammonia production of rabbit follicular oocytes matured in vitro. Experimental Cell Research 91 113-118

Bannai S (1984) Transport of cystine and cysteine in mammalian cells Biochimica et Biophysica Acta 779 289-306

Barnett DK and Bavister BD (1992) Hypotaurine requirement for in vitro development of golden hamster one-cell embryos into morulae and blastocysts, and production of term offspring from in vitro-fertilized ova Biology of Reproduction 47 297-304

Bavister BD (1989) A consistently successful procedure for in vitro fertilization of golden hamster eggs Gamete Research 23 139-158

Bavister BD (1995) Culture of preimplantation embryos: facts and artifacts Human Reproduction Update 191-148

Biggers JD, Whittingham DG and Donahue RP (1967) Pattern of energy metabolism in the mouse oocyte and zygote Proceedings of the National Academy of Sciences USA 58 560-567
Boatman DE and Magnoni GE (1995) Identification of a sperm penetration factor in the oviduct of the golden hamster Biology of Reproduction 52 199-207

Calvin HI, Grosshans K and Blake EJ (1986) Estimation and manipulation of glutathione levels in prepuberal mouse ovaries and ova: relevance to sperm nucleus transformation in the fertilized egg Gamete Research 14 265-275

De Felici M and Siracusa G (1982) Spontaneous hardening of the zona pellucida of mouse oocytes during in vitro culture Gamete Research 6 107-114

De Felici M, Dolci S and Siracusa G (1987) Involvement of thiol-disulfide groups in the sensitivity of fully grown mouse oocytes to calcium-free medium Journal of Experimental Zoology 243 283-287

De Matos DG, Furnus CC, Moses DF and Baldassarre H (1995) Effect of cysteamine on glutathione level and developmental capacity of bovine oocytes matured in vitro. Molecular Reproduction and Development $\mathbf{4 2}$ $432-436$

Fleming AD, Evans G, Walton EA and Armstrong DT (1985) Developmental capability of rat oocytes matured in vitro in defined medium Gamete Research 12 255-263

Funahashi H and Day BN (1993) Effects of the duration of exposure to hormone supplements on cytoplasmic maturation of pig oocytes in vitro. Journal of Reproduction and Fertility 98 179-185

Funahashi H, Cantley TC, Stumpf TT, Terlouw SL and Day BN (1994a) In vitro development of in vitro-matured porcine oocytes following chemical activation or in vitro fertilization Biology of Reproduction 50 1072-1077

Funahashi H, Stumpf TT, Terlouw SL, Cantley TC, Rieke A and Day BN (1994b) Use of low-salt culture medium for in vitro maturation of porcine oocytes is associated with elevated oocyte glutathione levels and enhanced male pronuclear formation after in vitro fertilization Biology of Reproduction 51 633-639

Grupen CG, Nagashima H and Nottle MB (1995) Cysteamine enhanced in vitro development of porcine oocytes matured and fertilized in vitro. Biology of Reproduction 53 173-178

Hanada A, Shioya Y and Suzuki T (1986) Birth of calves from nonsurgical transfer of blastocysts originated from in vitro fertilized oocytes matured in vitro (Abstract) 78th Annual Meeting of the Japanese Society for Zootechnological Science $1(36) 18$

Hillensjö T, Hamberger L and Ahrén K (1975) Respiratory activity of oocytes isolated from ovarian follicles of the rat Acta Endocrinologica (Copenhagen) $\mathbf{7 8}$ $751-759$

Issel RD, Nagele A, Ecker KG and Wilmanns W (1988) Promotion of cystine uptake and its utilization for glutathione biosynthesis induced by cysteamine and $\mathrm{N}$-acetylcysteine Biochemical Pharmacology $37881-888$

Kito S and Bavister BD (1996a) Maturation of hamster oocytes under chemically defined conditions and sperm penetration through the zona pellucida Zygote 4 199-210

Kito S and Bavister BD (1996b) Kinetics of sperm penetration and fertilization in vitro in hamster follicular and oviductal ova Journal of Experimental Zoology 274 373-383

Kito S and Bavister BD (1997) Gonadotropins, serum, and amino acids alter nuclear maturation, cumulus expansion and oocyte morphology in hamster cumulus-oocyte complexes in vitro. Biology of Reproduction 56 1281-1289

Laurincik J, Rath D and Nieman H (1994) Differences in pronuclear formation and first cleavage following in vitro fertilization between pig oocytes matured in vivo and in vitro. Journal of Reproduction and Fertility 102 277-284

Leibfried ML and Bavister BD (1983) Fertilizability of in vifro matured oocytes from golden hamsters Journal of Experimental Zoology 226 481-485

Longo FJ (1990) Dynamics of sperm nuclear transformations at fertilization. In Fertilization in Mammals pp 297-307 Eds BD Bavister, J Cummins and ERS Roldan. Serono Symposia, Norwell, MA

Lu LH, MacDonnell HF and Gordon I (1989) Birth of calves after in vitro maturation and fertilization of follicular oocytes Theriogenology 31 Abstract 222

McKiernan SH, Bavister BD and Tasca RJ (1991) Energy substrate requirements for in-vitro development of hamster 1-and 2-cell embryos to the blastocyst stage Human Reproduction 6 64-75

McKiernan SH, Clayton MK and Bavister BD (1995) Analysis of stimulatory and inhibitory amino acids for development of hamster one-cell embryos in vitro. Molecular Reproduction and Development 42 188-199

Meister A (1991) Glutathione deficiency produced by inhibition of its synthesis, and its reversal; application in research and therapy Pharmacology and Therapeutics 51 155-194

Moor RM and Smith MW (1979) Amino acid transport in mammalian oocytes Experimental Cell Research $119333-341$ 
Motlik J and Fulka J (1974) Fertilization of pig follicular oocytes cultivated in vitro. Journal of Reproduction and Fertility 36 235-237

Motlik J and Fulka J (1981) Fertilization of rabbit oocytes co-cultured with granulosa cells Joumal of Reproduction and Fertility $63425 \sim 429$

Perreault SD (1990) Regulation of sperm nuclear reactivation during fertilization. In Fertilization in Mammals pp 285-296 Eds BD Bavister, J Cummins and ERS Roldan. Serono Symposia, Norwell, MA

Perreault SD, Naish SJ and Zirkin BR (1987) The timing of hamster sperm nuclear decondensation and male pronucleus formation is related to sperm nuclear disulfide bond content Biology of Reproduction 36 239-244

Perreault SD, Barbee RR and Slott VL (1988) Importance of glutathione in the acquisition and maintenance of sperm nuclear decondensing activity in maturing hamster oocytes Developmental Biology 125, 181-186

Rose TA and Bavister BD (1992) Effect of oocyte maturation medium on in vitro development of in vitro fertilized bovine embryos Molecular Reproduction and Development $3172-77$

Schramm RD and Bavister BD (1994) Follicle-stimulating hormone priming of rhesus monkeys enhances meiotic and developmental competence of oocytes matured in vitro. Biology of Reproduction 51 904-912

Schramm D and Bavister BD (1995) Effects of granulosa cells and gonadotropins on meiotic and developmental competence of oocytes in vitro in nonstimulated rhesus monkeys Human Reproduction 10 887-895

Schroeder AC and Eppig JJ (1984) The developmental capacity of mouse oocytes that matured spontaneously in vitro is normal Developmental Biology 102 493-497

Schroeder AC, Downs SM and Eppig JJ (1988) Factors affecting the developmental capacity of mouse oocytes undergoing maturation in vitro. Annals of the New York Academy of Sciences 541 197-204

Shalgi R, Dekel N and Kraicer PF (1979) The effect of LH on the fertilizability and developmental capacity of rat oocytes matured in vitro. Journal of Reproduction and Fertility 55 429-435

Takahashi M, Nagai T, Hamano S, Kuwayama M, Okamura N and Okano A (1993) Effect of thiol compounds on in vitro development and intracellular glutathione content of bovine embryos Biology of Reproduction 49 228-232

Thibault CG (1972) Final stages of mammalian oocyte maturation. In Oogenesis pp 397-411 Eds. JD Biggers and AW Schuetz. University Park Press, Baltimore, Butterworth, London

Thibault C and Gerard M (1973) Cytoplasmic and nuclear maturation of rabbit oocytes in vitro. Annales de Biologie Animale, Biochimie, Biophysique 13 (Supplement) 145-I56
Wright SJ and Longo FJ (1988) Sperm nuclear enlargement in fertilized hamster eggs is related to meiotic maturation of the maternal chromatin Journal of Experimental Zoology 247 155-165

Yanagida K, Yanagimachi R, Perreault SD and Kleinfeld RG (1991) Thermostability of sperm nuclei assessed by microinjection into hamster oocytes Biology of Reproduction 44 440-447

Yanagimachi R (1994) Mammalian fertilization. In Physiology of Reproduction (2nd Edn) pp 135-186 Eds E Knobil and ID Neill. Raven Press, New York

Yoo E (1990) Spontaneous activation and cleavage in unfertilized ova of the golden hamster (Mesocricetus auratus) Biology of Reproduction 42 (Supplement 1) 93

Yoshida M (1993) Role of glutathione in the maturation and fertilization of pig oocytes in vitro. Molecular Reproduction and Development 35 76-81

Yoshida M, Ishigaki K and Pursel VG (1992) Effect of maturation media on male pronucleus formation in pig oocytes matured in vitro. Molecular Reproduction and Development 31 68-71

Yoshida M, Ishigaki K, Nagai T, Chikyu M and Pursel VG (1993a) Glutathione concentration during maturation and after fertilization in pig oocytes: relevance to the ability of oocytes to form male pronucleus Biology of Reproduction 49 89-94

Yoshida M, Mizoguchi Y, Ishigaki K, Kojima T and Nagai T (1993b) Birth of piglets derived from in vitro fertilization of pig oocytes matured in vitro. Theriogenology 39 1303-1311

Younis AI, Brackett BG and Fayrer-Hosken RA (1989) Influence of serum and hormones on bovine oocyte maturation and fertilization in vitro. Gamete Research 23 189-201

Zar JH (1984) Biostatistical Analysis Prentice-Hall, Englewood Cliff, NJ

Zhang X, Rutledge J and Armstrong DT (1991) Studies on zona hardening in rat oocytes that are matured in vitro in a serum-free medium Molecular Reproduction and Development 28 292-296

Zirkin BR, Perreault SD and Naish S (1989) Formation and function of the male pronucleus during mammalian fertilization. In The Molecular Biology of Fertilization pp 91-114 Eds H Schatten and G Schatten. Academic Press, San Diego

Zuelke KA and Brackett BG (1992) Effects of LH on glucose metabolism in cumulus-enclosed bovine oocytes matured in vitro. Endocrinology 131 2690-2696

Zuelke KA and Brackett BG (1993) Increased glutamine metabolism in bovine cumulus cell-enclosed and denuded oocytes after in vitro maturation with $\mathrm{LH}$ Biology of Reproduction 48 815-820 